\title{
Evan Weissman: Remembering our advisor, professor, and comrade
}

\author{
The Syracuse University Food Studies Graduate Students * \\ Syracuse University
}

Submitted February 2, 2021 / Published online September 16, 2021

Citation: The Syracuse University Food Studies Graduate Students. (2021). Evan Weissman:

Remembering our advisor, professor, and comrade. Journal of Agriculture, Food Systems, and

Community Development, 10(4), 5-7. https://doi.org/10.5304/jafscd.2021.104.014

Copyright (C) 2021 by the Author. Published by the Lyson Center for Civic Agriculture and Food Systems. Open access under CC-BY license.

$I^{n}$

n the early spring of 2020, the Syracuse University community was dealt a sudden and painful blow with the loss of Dr. Evan Weissman. It is to his vibrant memory that this special issue of the Journal of Agriculture, Food Systems, and Community Development is dedicated. What follows are the reflections of the special issue's guest editorial team and our peers in the Syracuse University Food Studies graduate program - a program and department that Evan helped to create shortly after completing his own graduate education at Syracuse University.

Evan was the very reason many of us came to Syracuse University or stayed in the city to pursue our graduate educations. He was, and remains, a model for a particular kind of scholarship, which was the inspiration for the theme of this special issue. He was a community-engaged scholar in the truest sense, and likewise encouraged students to commit themselves to becoming active participants in food systems change. Moreover, he had an unwavering belief that this was something we could do, that if we were willing to put in the work, as he did all the time, we could play a part in working toward a more just world. Evan's commitment to his community and his deep belief that food could be used as a tool for social change have influenced many of us to undertake active roles in our own cities, be it managing a network of community gardens, overseeing an anti-poverty initiative, or fighting for workers' rights.

Talking with Evan, one thing that was immediately clear was his genuine curiosity about people-a much-needed antidote to an academic world in which students can feel overlooked to the point of being

* Corresponding author: Katie Mott, Ph.D. Student, Department of Sociology, Syracuse University; 302 Maxwell Hall; Syracuse, NY 13244 USA; 1 lmott@syr.edu 
lost. Not surprisingly, much of this curiosity revolved around food, and everyone has an Evan story that involves his attempt to discover, or uncanny ability to remember, their favorite food. But of course, food was a mode of expression, and of connection. He met with a stressed advisee at a local restaurant and, remembering her love of cheese, made a plate of fried cheese curds appear on the table. Arriving back from a trip to Quebec, he surprised a homesick Canadian with her favorite north-of-the-border-exclusive Super Nibs and Hawkins Cheezies. Before cofacilitating a conference session with his anxious advisee, Evan calmed their nerves over lunch and was the first to celebrate them with drinks, dancing, and latenight tacos when the session turned out to be a success.

Beyond food, Evan viewed us not as one-dimensional graduate students, but as friends and intellectual equals. He made clear his understanding that life outside of academia presents its own set of unique challenges and hardships. When those challenges undoubtedly arose, he helped us however he could, whether that meant an extension on a paper or grabbing a drink to ease our mind. Missing a deadline or running late to a meeting meant very little to Evan-whether the offender was a student or Evan himself.

His concern was less for rules or procedure than for being fully present in each moment. In the middle of finals week, when papers and projects were due and everyone, including professors, were working past their limits, he took an overwhelmed student down to a local bar, bought them lunch and a beer, and watched the first half of a Champions League soccer match. Whether we wanted to talk to him about future career paths, how to tackle a research project, debate the moves the Mets made during the offseason, argue over whether Tottenham (his favorite soccer team) had the right pieces to win the Premier League, or catch up on the latest local gossip, Evan was there for us. Through these experiences, we got to know Evan beyond the great professor, researcher, and activist-scholar he was. We got to know him as simply a very good, and very funny, person.

As teaching assistants, we witnessed Evan's knack for teaching students from varying disciplines and backgrounds, with differing levels of interest and familiarity with the food system. He handled this dynamic beautifully, as he could articulate concepts clearly and keep his students' attention through project-based and community-oriented curriculum. Whenever the opportunity presented itself, Evan shared his dedication to and care for Syracuse, encouraging us to think differently about a city so often characterized only by its post-industrial decline. Through his Urban Food Systems course, he pushed undergraduate students to fully experience Syracuse, pairing students with nonprofit organizations to carry out mutually beneficial projects and develop students' understanding of the city beyond the University Hill. Through the Farm to Fork course, Evan broke bread with students and explored various farms in Central New York. He was unafraid of the more monotonous or unattractive tasks, such as demonstrating milking goats or cleaning up the kitchen when class ran over time, knowing that his efforts would provide students with the best possible learning environment.

The success of Evan's teaching style was clearly demonstrated by the sheer number of students, within and outside of the department, who visited his office to talk with him about a particular class reading, a research project they were involved in, how to become a food studies major or minor, or simply how to navigate college. Not only was Evan a role model we had the privilege to observe, but he also offered us countless opportunities to develop our own teaching skills. He encouraged teaching assistants to lead classes and review sessions before exams, learn the tedious art of grading, and participate in syllabus construction. Evan cared deeply about our growth both as students and future teachers. Many of us now model our teaching on his own-his ability to truly connect with students and discover what made them tick.

Another facet of Evan's teaching style was demonstrated in his graduate seminar, The Political Economy of Food. Although it was one of the more rigorous courses in the graduate program, he had a 
keen ability to capture students' attention and transform complex, intimidating, and even mundane concepts into engaging, easily digested, and interesting material. Evan was a professor who thoroughly loved teaching and, even more, transforming his students into critical thinkers and future food system practitioners.

Evan was teaching this course in March 2020, shortly before his passing, and during the escalating coronavirus pandemic. He responded to the crisis in typical style, making it clear to students that he had no interest in overburdening them with coursework, and turned the seminar time instead into a regular meeting at which students, isolated in quarantine, could meet, share news, and discuss various Syracusebased mutual aid and other efforts in which to take part. This, of course, was not atypical of Evan, who even under less extraordinary circumstances expressed genuine concern for students' welfare, carving out space during or after class to listen to distressed students. When an advisee was faced with grave health concerns, Evan immediately prioritized their health, finding every way to support them through their recovery and cheering them on at their eventual thesis defense. He was an anchor of the food studies program and our experiences within that program.

Evan was kind and, just as importantly, he was honest. He inspired rigor and dedication in the students he taught and advised. For many Food Studies students, Evan was the person we implicitly turned to for sound advice or thoughtful feedback. He still is, and for many of us not a day goes by that we do not find ourselves wanting to email him, or (as he much preferred) call him up, with a question or seeking some bit of advice. There were few instances when Evan did not have the perspective, answer, or solution we needed. Yet, even then, in those rare moments when Evan was also at a loss, his unwavering solidarity gave us hope.

It is this absence that is perhaps felt most keenly, and it is decidedly unfair that future students will not experience Evan's mentorship. Navigating the loss of our advisor, professor, and comrade has made more painfully obvious Evan's immeasurable worth, and it is difficult to imagine anyone as capable of shouldering his seemingly endless roles. More than that, however, is the simple fact that we miss him terribly. 